\title{
Development of Neural Network Model for Predicting Peak Ground Acceleration Based on Microtremor Measurement and Soil Boring Test Data
}

\author{
T. Kerh, ${ }^{1}$ J. S. Lin, ${ }^{1}$ and D. Gunaratnam ${ }^{2}$ \\ ${ }^{1}$ Department of Civil Engineering, National Pingtung University of Science and Technology, \\ Pingtung 91207, Taiwan \\ ${ }^{2}$ Faculty of Architecture, Design and Planning, University of Sydney, Sydney, NSW 2006, Australia
}

Correspondence should be addressed to T. Kerh, tfkerh@gmail.com

Received 20 August 2012; Accepted 20 September 2012

Academic Editor: Ju H. Park

Copyright (C) 2012 T. Kerh et al. This is an open access article distributed under the Creative Commons Attribution License, which permits unrestricted use, distribution, and reproduction in any medium, provided the original work is properly cited.

It may not be possible to collect adequate records of strong ground motions in a short period of time; hence microtremor survey is frequently conducted to reveal the stratum structure and earthquake characteristics at a specified construction site. This paper is therefore aimed at developing a neural network model, based on available microtremor measurement and on-site soil boring test data, for predicting peak ground acceleration at a site, in a science park of Taiwan. The four key parameters used as inputs for the model are soil values of the standard penetration test, the medium grain size, the safety factor against liquefaction, and the distance between soil depth and measuring station. The results show that a neural network model with four neurons in the hidden layer can achieve better performance than other models presently available. Also, a weight-based neural network model is developed to provide reliable prediction of peak ground acceleration at an unmeasured site based on data at three nearby measuring stations. The method employed in this paper provides a new way to treat this type of seismic-related problem, and it may be applicable to other areas of interest around the world.

\section{Introduction}

Earthquake problems are globally considered to be a research topic of importance since many countries are subject to this natural disaster. For instances, the recent big one with magnitude 9.0 on the Richter scale that occurred in Japan on 11 March 2011 and triggered a significant tsunami, caused approximately \$35 billion in damage. On 12 January 2010, a devastating earthquake with magnitude 7.0 on the Richter scale struck Haiti in the Caribbean, and claimed more than 200 thousand lives have lost in the capital and surrounding areas. 
Other major earthquakes experienced by Chile, China, Indonesia, New Zealand, and Taiwan are listed in the archive of United States Geological Survey [1]. Without exception, all these earthquakes have caused tremendous casualties and property losses, requiring urgent attention to this calamitous problem.

Many seismic-related research issues have been investigated and published previously, with some focused on finding an early warning system, while others are based on records of historical seismic data (e.g., [2-8]). It is quite obvious that strong ground motions data cannot be collected in a short period of time, and also the records for a metropolitan area or a place with high population density are not easy to obtain. Whereas, microtremor surveys can be used to infer the stratum structure and earthquake characteristics at a specified construction site without destroying its ground surface. Thus, this fast and low cost measuring technique is often selected not only to provide useful information for an area which lacks seismic records, but also to effectively analyze potential liquefaction index for the construction site being investigated.

Further, it is worth mentioning that the microtremor measurements with appropriate transformation, such as Fourier transform or Nakamura technique, can estimate the key seismic parameter, that is, peak ground acceleration (PGA), which exhibits a tendency similar to the characteristics of strong ground motion $[9,10]$. Note that the above literatures were focused on the development of neural network models based on actual seismic records, and microtremor measurements were used for the sake of comparison. Regarding the development of neural network model in accordance with microtremor measurement and soil profile was not examined in these studies. Also, some important factors such as dominant frequency, shear wave speed, and amplification can be explored by microtremor surveys [11-18], and these can help to determine the distribution of soil layers, liquefaction hazard mapping, and earthquake site response. Although microtremor measurements can be easily carried out at a number of sites, the main limitation is the increase in cost with increased number of measuring stations. Hence, the development of a model for predicting microtremor information for other important but unmeasured sites is useful for economic reasons.

From the references mentioned above and other reports previously published in the field of earthquake engineering and soil dynamics, the microtremor measurements appear to be a function of the soil conditions at a specified site. However, prediction of microtremor information by using soil boring test result has rarely been reported up to now. Therefore, the purpose of this study is to develop a model for mapping soil boring test data to microtremor measurements by using a neural network approach. In particular, three key soil parameters; the standard penetration test value (STP-N), the medium grain size (D50), and the safety factor against liquefaction (FL), and one spatial factor, that is, the distance between soil layer and measuring station (DS), are used to evaluate PGA resulting from microtremor measurements. A weight-based neural network model is also developed to predict PGA at unmeasured sites by using values at three nearby measuring stations. The method developed in this study should provide a new approach for solving problems in the relevant engineering field.

\section{Context and Rationale for the Research}

Science parks are mainly occupied by many high-tech companies including some world class factories such as ACER, HTC, and TSMC, which play an important economic role in the 
island of Taiwan. In this study, the chosen Kaohsiung (Luchu) science park is one of the major parks located in the southern part of Taiwan. This park has a total area of 571 hectares, which started construction in the year of 2001 and was completed in 2010. Various hightech industries, such as integrated circuits, precision machines, optoelectronic components, computer peripherals, communication and biotechnology products, were planned and developed in this park. These types of industries can be affected significantly by strong ground motions and are also sensitive to ambient vibrations. Therefore, it is necessary to consider antiearthquake design and to examine microtremor in the park from time to time to prevent different levels of damages.

Two crucial factors for evaluating the effect of ground motions in the science park are fault distribution and geological condition in Kaohsiung area, which are based on the information from Central Geological Survey shown in Figure $1[19,20]$. It can be seen that there exists seven faults in this region, which are (1) Chishan fault, (2) Liukuei fault, (3) Tsaujou fault, (4) Hsiaokangshan fault, (5) Yuchang fault, (6) Jenwu fault, and (7) Fengshan fault. These faults may create strong ground motions and endanger the high-tech buildings and instruments. Also from this figure, it can be seen that alluvial soil occupies a large part of Kaohsiung area, particularly at the science park, which can have an influence on microtremor measurements.

The occurrence of strong ground motion is unpredictable, and it can cause serious structural damage within a very short period of time. Thus, a proper antiearthquake design is usually considered for high-tech factory constructions. In contrast, the existence of microtremor is easy to neglect as it is very small, but due to microtremor occurring very often on the earth surface, some precision instruments can be damaged during its operation process due to the constant continuous vibration frequency or peak ground acceleration. Consequently, microtremor can cause, for high-tech manufactures, an unexpected and significant financial loss, and thus environmental ambient vibration survey is a very important consideration for science parks.

Figure 2 shows the Kaohsiung science park, with four microtremor measuring stations MS1, MS2, MS3, and MS4. Also, there are twenty-seven soil boring test sites in the neighborhood of this park. As mentioned previously, this study is focused on the development of a model for predicting peak ground acceleration based on microtremor measurements and soil boring test data. Therefore, the records obtained from these measuring stations and boring test sites can provide useful information for developing the model by using neural network approach. In the next section, the processing of measured and test data is discussed, and then the results obtained from the developed model are presented.

\section{Ambient Vibration Measurement and Soil Boring Test Data}

Ambient vibration with very low amplitude (about $10^{-6} \mathrm{~m}$ ) and acceleration $(0.8-2.5$ gal or $\mathrm{cm}^{2} / \mathrm{s}$ ), which cannot in general be felt by humans [21, 22], is frequently found on the ground surface of the earth. This vibration, however, can be recorded by using a precise measuring instrument developed recently. In the present study, the results of ambient vibrations are measured and calculated by a set of ultrasensitive seismic accelerometer-Model 731A-made by Wilcoxon with other monitoring instrument and computer software [23-25]. The original microtremor information is stored in the frequency and time domains, but only the data set in time domain is considered for analysis as the characteristics of ground motion is the primary concern in this study. 


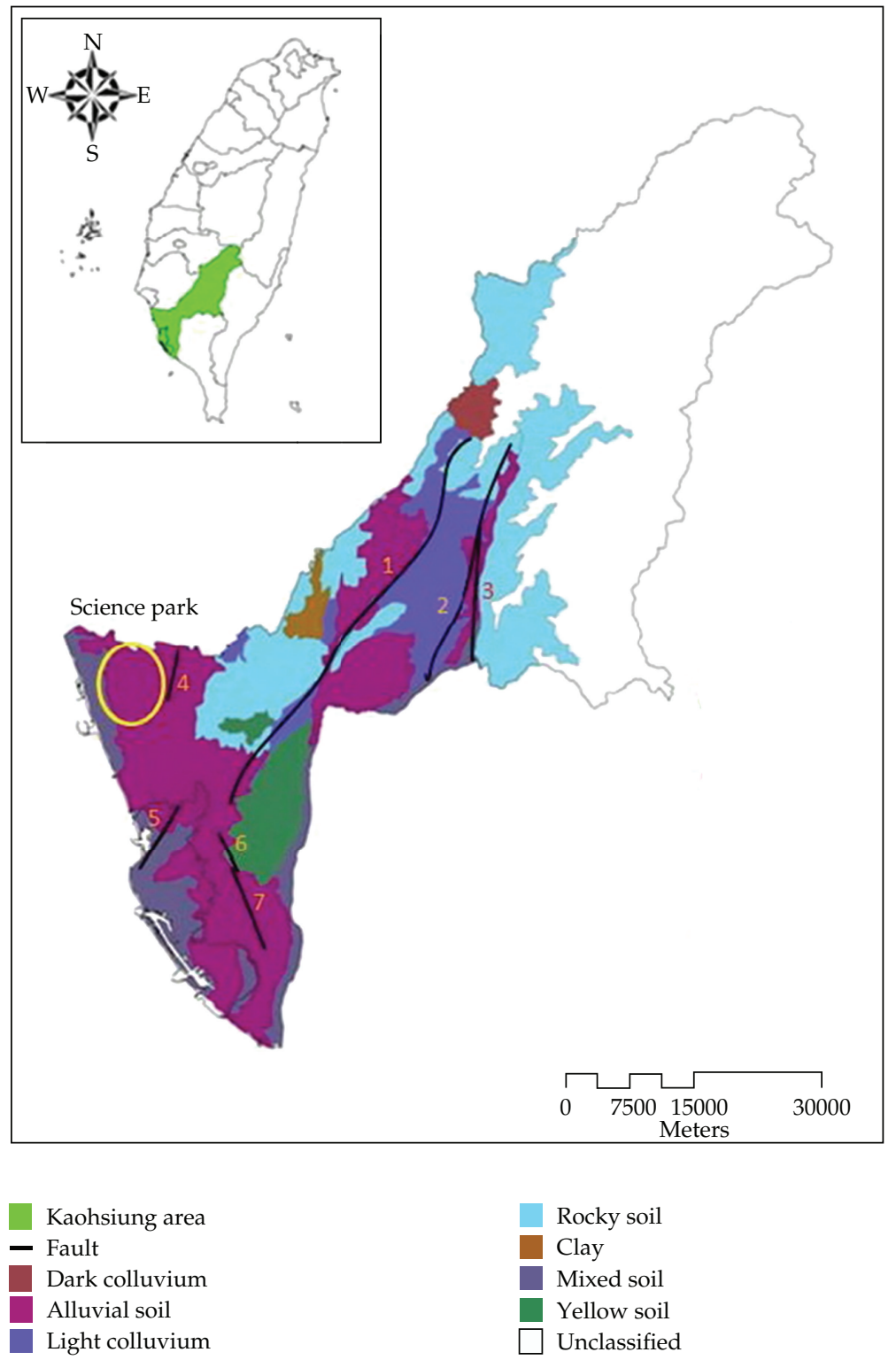

Figure 1: Distribution of faults and geological conditions in the Kaohsiung area.

From microtremor data collected at the four measuring stations, it can be found that the accelerations for measuring station MS1 are basically in the range 0.43 gal to 51.71 gal in both the east-west (EW) and north-south (NS) directions, and the results in vertical (V) direction are all smaller than 0.58 gal. For measuring station MS2, the results are 0.33 gal24.1 gal, 0.27 gal-47.49 gal, and 0.78 gal-80.19 gal, in EW, NS, and V directions, respectively. For measuring station MS3, the results are 0.33 gal-5.03 gal, 0.27 gal-4.29 gal, and 0.31 gal6.13 gal, in EW, NS, and V directions, respectively. For measuring station MS4, the results are 0.58 gal-45.85 gal, 0.34 gal-15.46 gal and 1.05 gal-49.52 gal, in EW, NS and V directions, respectively. 


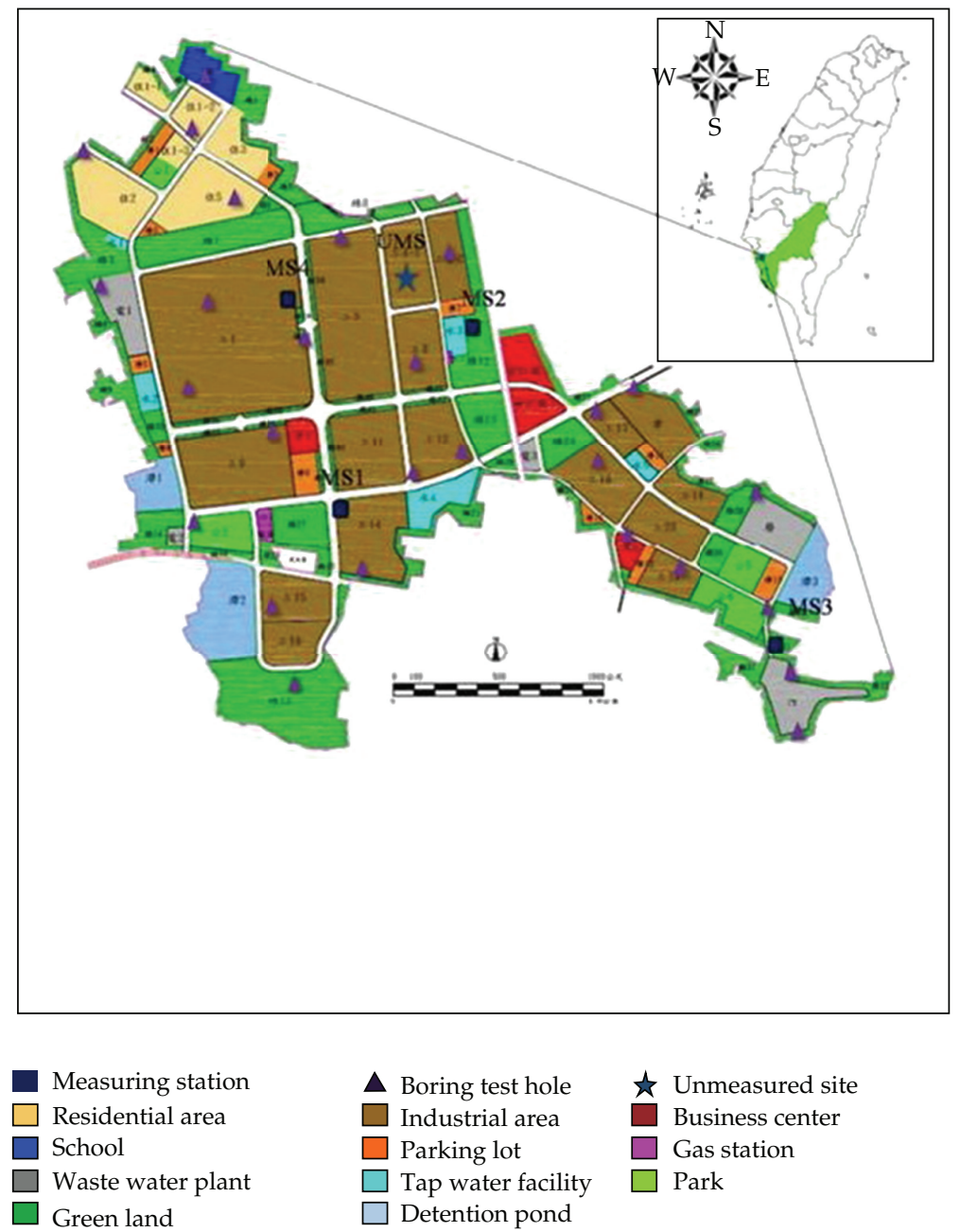

Figure 2: Sketch of research area in Kaohsiung science park.

The above numerical results show that the accelerations in the vertical direction are all relatively higher than those of the other directions, except at the measuring station MS1. As ambient vibrations may result from moving vehicles and construction work, some of the measured data may exhibit much higher values particularly between 8:00 AM and 5.00 PM, and these can affect the true microtremor response. Therefore, in this study, only ambient vibration data collected between 8:00 PM and 7:00 AM are taken for analysis so as to eliminate outside environmental factors as far as possible and increase the accuracy of natural microtremor response measurements.

For soil test data in the boreholes, the samplings are by auger boring method for soils above ground water level and by the method of wash boring for soils below ground water level. The laboratory tests conducted were for general physical, triaxial compression, shear strength, unconfined compressive strength, consolidation, compaction, California bearing ratio, resilient modulus, and groundwater quality. The in-situ tests were for lateral load and 
Table 1: Typical values of soil parameters and random PGAs in the four directions.

\begin{tabular}{lccccccc}
\hline \multicolumn{7}{c}{ Measuring station MS1 } \\
STP-N & D50 $(\mathrm{mm})$ & FL & DS $(\mathrm{m})$ & PGA $($ EW $)$ & PGA (NS) & PGA (V) & PGA (H) \\
\hline 7 & 0.022 & 2.20 & 412.19 & 1.82 & 1.69 & 4.44 & 2.48 \\
2 & 0.006 & 1.75 & 412.21 & 2.09 & 2.02 & 4.53 & 2.90 \\
14 & 0.030 & 2.00 & 412.23 & 1.23 & 2.38 & 7.40 & 2.67 \\
10 & 0.062 & 1.27 & 412.26 & 1.89 & 1.74 & 4.45 & 2.56 \\
6 & 0.006 & 1.57 & 412.31 & 8.38 & 12.6 & 5.35 & 15.13 \\
34 & 0.150 & 1.17 & 412.36 & 1.89 & 3.61 & 5.67 & 4.07 \\
37 & 0.160 & 1.17 & 412.42 & 1.44 & 1.96 & 4.33 & 2.43 \\
43 & 0.160 & 1.22 & 412.50 & 0.61 & 0.84 & 4.25 & 1.03 \\
27 & 0.160 & 1.01 & 412.58 & 0.58 & 1.29 & 4.43 & 1.41 \\
13 & 0.026 & 1.79 & 412.67 & 2.50 & 4.84 & 8.43 & 5.44 \\
$\ldots$ & $\ldots$ & $\ldots$ & $\ldots$ & $\ldots$ & $\ldots$ & $\ldots$ \\
\hline \multicolumn{7}{c}{. } & \multicolumn{7}{c}{ Total data sets: 50; PGA unit: gal } \\
\hline
\end{tabular}

permeability. All of these test results can provide soil characteristics in detail for each of the drilling sites.

For a typical soil exploration and testing report in the research area, it can be seen that there are many items such as soil depth, soil profile, USCS (unified soil classification system) classification, standard penetration value, grain size analysis, water content, specific gravity, density, void ratio, liquid limit, plasticity index, and safety factor against liquefaction calculated from shear strength parameters [26]. Note that some of these soil test items may have their own physical meaning and also have a relationship with each other. Previous studies have found that the three important parameters relevant to the problem of actual earthquake response are STP-N, D50, and FL [27-29]. Hence, these three parameters, with ambient vibration surveys and distance between measuring station and test layer within bore hole (DS), are considered for developing a PGA prediction model by the neural network approach. Typical values for STP-N, D50, FL, DS, and PGA in the four directions are shown in Table 1.

\section{Neural Network Model and Analysis of Prediction Results}

In the field of computational intelligence, neural network approach is widely applied in various engineering applications as it has some attractive features such as easiness to implement, strong pattern recognition capability, and good prediction performance [3032]. Basics of neural network modeling such as selecting a suitable architecture, learning algorithms, preprocessing of data, training, and testing of models have been comprehensively covered in many publications [33-35]. Thus, further discussions of this method and the use of associated software tool are not included here, but only some of the key points for using this computational technique that are relevant to the present research problem are addressed below.

To develop a neural network model, it is essential to determine the number of neurons in the input layer, the hidden layer, and the output layer. In this study, five soil boring test data in the neighborhood of each microtremor measuring station are used in developing the model. As mentioned in the previous section, the soil input parameters included are STP-N, 


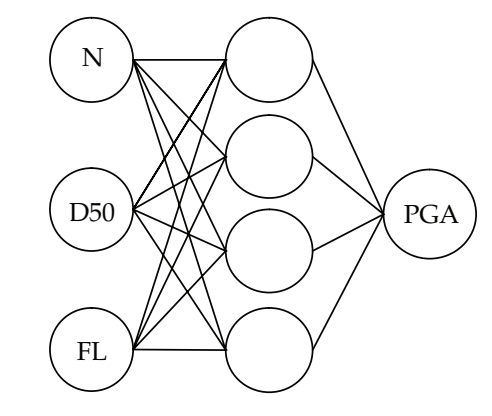

Input layer Hidden layer Output layer

(a)

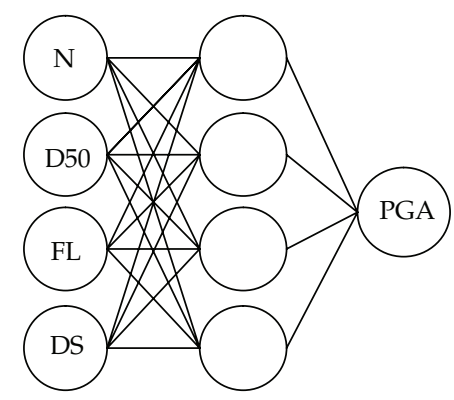

Input layer Hidden layer Output layer

(b)

Figure 3: Sketch of neural network models $\mathrm{I}_{3} \mathrm{H}_{4} \mathrm{O}_{1}$ (a) and $\mathrm{I}_{4} \mathrm{H}_{4} \mathrm{O}_{1}$ (b).

D50, and FL. Therefore, a total of 50 data sets are available for the five bore holes, as each bore hole has a $20 \mathrm{~m}$ depth, and the soil profile is divided into 10 layers. If the distance parameter DS defined previously is also included, then there are four neurons in the input layer. The PGA in each of the different directions (EW, NS, V, and $\mathrm{H}$ ) obtained from microtremor measurements is used as the target, resulting in only one neuron in the output layer. The number of neurons in the hidden layer needs to be selected to provide a relatively better performing neural network model.

It is better to examine the input soil data sets in advance to find a suitable neural network prediction model. Initially, we consider a neural network model without the distance parameter as shown in Figure 3(a), and divide the normalized data sets into three groups, where $70 \%$ is for training, $20 \%$ for verification, and $10 \%$ for testing. These three calculation stages are performed in Matlab toolbox with the "train," "adapt," and "simulate" functions $[36,37]$. The computational experiments, with the use of correlation coefficient $(R)$ as evaluation index, showed that the training result can achieve high $R^{2}$ values (from 0.656 to 0.900 ) with random data selection in the network calculation, but it has a poor performance in the verification cases (from 0.004 to 0.235 ) and the testing cases (from 0.001 to 0.361 ), as seen in Table 2. The poor performance of this model is due to random data selection with no rational basis for the association of the PGA values that are collected over time with the soil properties that are defined spatially within the bore holes. Thus, a rational basis for associating the data values for the input and output variables is required, and available domain knowledge is used as the basis for this association.

Because the STP-N value refers to soil hardness, it can play an important role in influencing the degree of liquefaction during an earthquake. Hence, by taking the STP-N as the primary factor and arranging its data set to increase from small to large values, with corresponding adjustments to the other input parameters, the target PGA data set is then arranged from large to small values. Again, without considering the distance parameter in the input layer, the performances of the neural network models with different number of neurons in the hidden layer were considered, and the model with four neurons in the hidden layer has a relatively better performance than the other models for all three calculation stages.

Note that only 50 data sets were used for developing neural network model in this study, so it is not suitable to choose too many layers or neurons in the hidden layer as it may cause ineffective learning during the training stage. The neural network model with 
Table 2: Performance of neural network model $\left(\mathrm{I}_{3} \mathrm{H}_{4} \mathrm{O}_{1}\right)$ in different calculation stages.

\begin{tabular}{lcccccccccccc}
\hline \multirow{2}{*}{ Station } & \multicolumn{4}{c}{ Training $\left(R^{2}\right)$} & \multicolumn{4}{c}{ Verification $\left(R^{2}\right)$} & \multicolumn{4}{c}{ Testing $\left(R^{2}\right)$} \\
& EW & NS & V & H & EW & NS & V & H & EW & NS & V & H \\
\hline MS1 & 0.762 & 0.682 & 0.892 & 0.768 & 0.145 & 0.235 & 0.015 & 0.018 & 0.236 & 0.349 & 0.028 & 0.067 \\
MS2 & 0.656 & 0.782 & 0.900 & 0.834 & 0.013 & 0.004 & 0.020 & 0.026 & 0.271 & 0.361 & 0.001 & 0.132 \\
MS3 & 0.758 & 0.689 & 0.821 & 0.740 & 0.019 & 0.120 & 0.095 & 0.087 & 0.235 & 0.165 & 0.059 & 0.017 \\
\hline
\end{tabular}

Table 3: Performance of neural network models $\left(\mathrm{I}_{4} \mathrm{H}_{4} \mathrm{O}_{1}\right)$ for the three measuring stations.

\begin{tabular}{lcccccccccccc}
\hline \multirow{2}{*}{ Station } & \multicolumn{4}{c}{ Training $\left(R^{2}\right)$} & \multicolumn{4}{c}{ Verification $\left(R^{2}\right)$} & \multicolumn{4}{c}{ Testing $\left(R^{2}\right)$} \\
& EW & NS & V & H & EW & NS & V & H & EW & NS & V & H \\
\hline MS1 & 0.996 & 0.999 & 0.999 & 0.999 & 0.820 & 0.766 & 0.897 & 0.926 & 0.847 & 0.760 & 0.706 & 0.847 \\
MS2 & 0.997 & 0.992 & 0.995 & 0.997 & 0.918 & 0.656 & 0.726 & 0.761 & 0.815 & 0.728 & 0.737 & 0.601 \\
MS3 & 0.996 & 0.999 & 1.000 & 0.999 & 0.877 & 0.878 & 0.736 & 0.893 & 0.774 & 0.755 & 0.697 & 0.762 \\
\hline Average & 0.996 & 0.997 & 0.998 & 0.998 & 0.872 & 0.767 & 0.786 & 0.860 & 0.812 & 0.747 & 0.714 & 0.737 \\
\hline
\end{tabular}

four neurons in the hidden layer is found to be more reliable and will also be used with the distance parameter in the input layer.

Table 3 shows the performance of the preferred neural network model $\mathrm{I}_{4} \mathrm{H}_{4} \mathrm{O}_{1}$ (Figure 3(b) for the three microtremor measuring stations. It can be seen that the average $R^{2}$ values are quite high and up to 0.998 at the training stage. The average $R^{2}$ values range from 0.767 to 0.872 at the verification stage and from 0.714 to 0.812 at the testing stage, all exhibiting reasonably high coefficient of correlation between measurement and estimation. That is, the developed neural network model has a sufficient level of prediction capability and can be used for further investigation.

The above results from the neural network models demonstrate that microtremor measurements may have a relationship to the soil profile. It is crucial to check the capability and apply the developed model for predicting PGA at an unmeasured site. To perform this task, it can be assumed that microtremor measuring station MS4 is an unknown site, then the known PGA values at this station can be used for verifying the ability of neural network model. To estimate PGA in station MS4 from the three known stations MS1, MS2, and MS3, the straightforward method is by distributing the results of these three known stations with weighting factors based on the distances between stations and denoted here by "Model 1."

Alternatively, a better way to estimate PGA at an unmeasured site is by taking a new set of soil data from five drilling holes nearby, and insert the data set solely to the neural network model developed for each of known measuring stations. Then by summing the results with weighting factors in accordance with the distances between the unknown site to the three known stations, the final estimation is obtained for the unknown site, and this method is denoted here as "Model 2".

The comparison of prediction results for the two models and microtremor measurements in the different directions are shown in Figure 4. It can be seen that the neural network estimations are not too different for both models, but the results of "Model 2" seem to be slightly closer to the actual measurements. Because the total recorded ambient vibration surveys for MS4 are 70 data sets, the chosen 50 data sets cover a wider range of time interval compared to the other three stations. Therefore, some of the measurements exhibit higher values (PGA $>0.005 \mathrm{~g}$ ), particularly for the east-west and vertical directions, and these may 


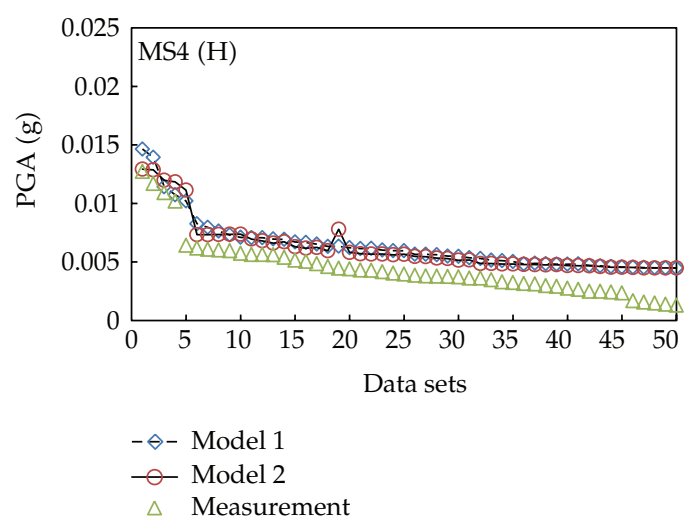

(a)

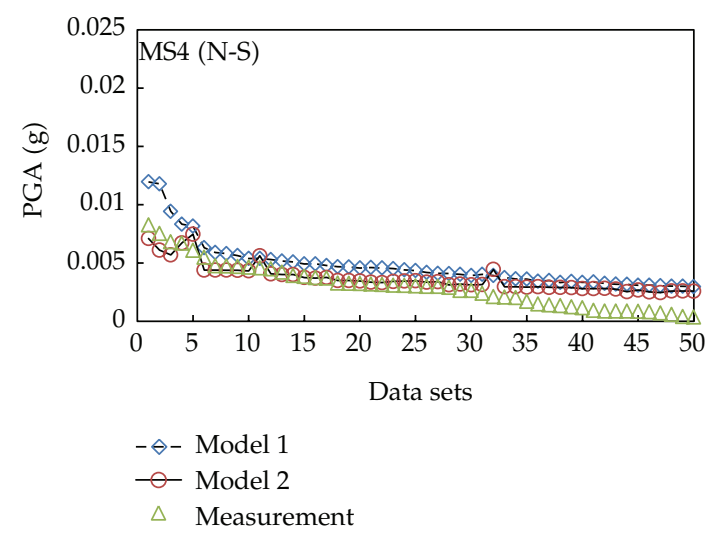

(c)

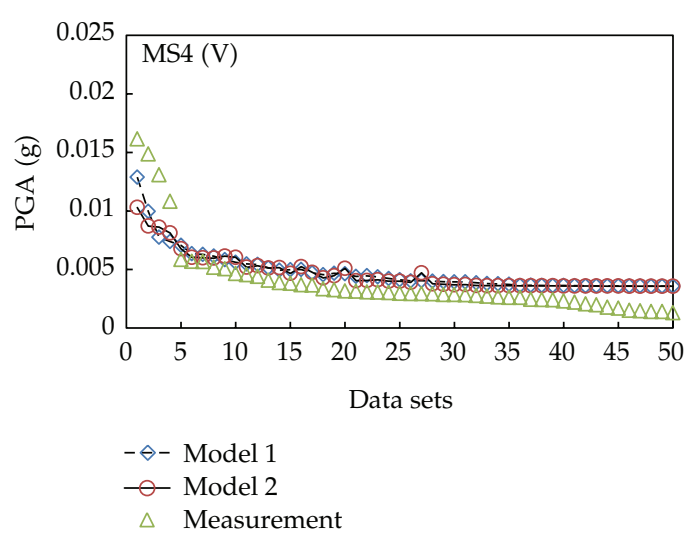

(b)

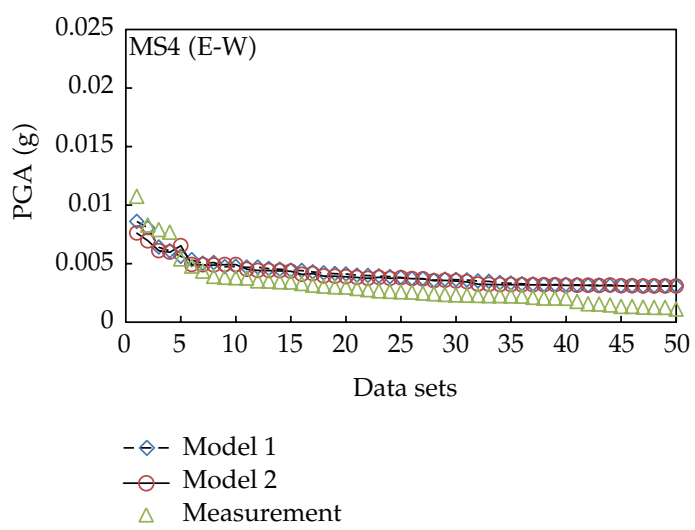

(d)

Figure 4: Comparison of neural network estimations and actual measurements.

cause an error in the prediction. In general, the performances of both neural network methods have reasonable accuracy and are acceptable for the problem considered. This comparison of results provides confidence for using this method for prediction of PGA in an unmeasured but important site.

Installation of ambient vibration survey instrument is usually at a place where the density of high-tech buildings is not too high. Thus, this method is suitable for an unmeasured site (UMS) shown in Figure 2, which is closer to several important industrial buildings and is possibly sensitive to natural microtremor. The present approach of developing neural network model is thus very useful for predicting PGA at this site with the use of new soil data sets from nearby five bore holes. Figure 5 shows the prediction result for the unmeasured site. It can be seen that both models exhibit similar predictions, but the curve obtained from "Model 2" is not as smooth as for "Model 1." The reason may be that the soil bore holes used in one of the known measuring stations, MS3, are too far away from the unmeasured site. Actually, this local instability problem is also found in the previous comparison shown in Figure 4, but it is believed that the present neural network model should still be sufficiently reliable. The sequential selection of the data sets for developing the neural network models results in the networks predicting the results for the test data 


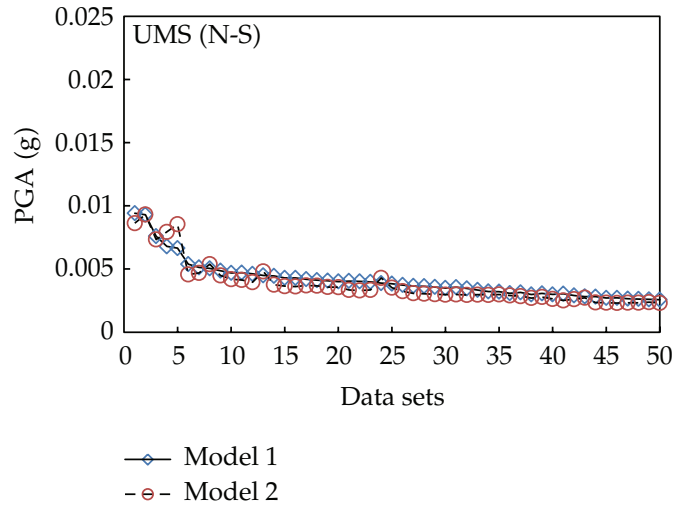

(a)

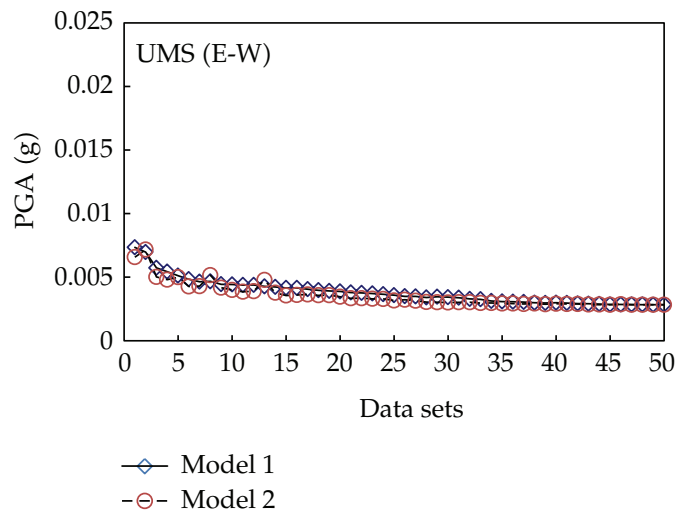

(c)

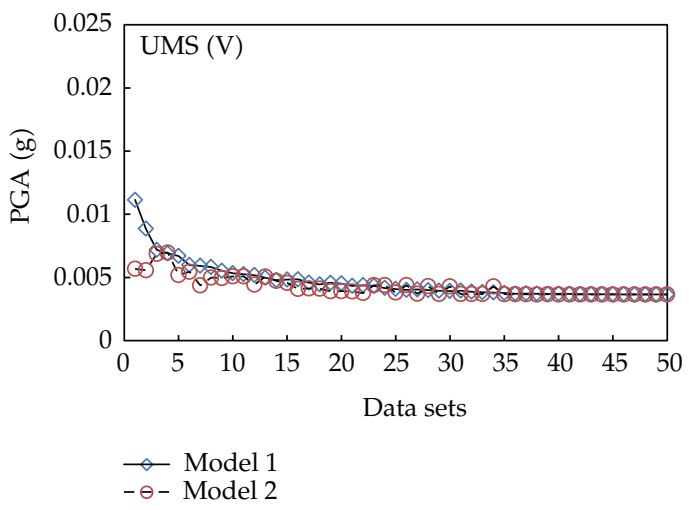

(b)

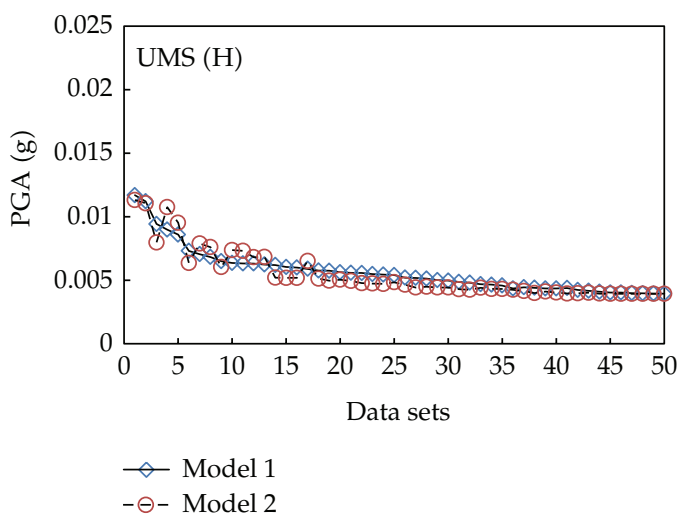

(d)

Figure 5: Predicted PGA at an unmeasured site in different directions.

sets by extrapolation. This accounts for the difference between the model predictions and the measurements on the right hand side of the curves in Figure 4. The predictions could be further improved by a random selection of data sets, for training, verification, and testing, after the reordering of the data sets as described previously.

If the measured results in the closest station MS2 are taken as reference, then the prediction result shows that PGA in vertical direction is larger than the other two directions, which is consistent with the measured results, and this is also true for predicted PGA in the horizontal direction. Since this science park is mostly alluvial soil, the prediction result is thus reasonable as there is no significant change of soil conditions in the unmeasured site. Overall, the neural network "Model 2" seems more preferable as the distance parameter and new soil data set are used in the calculation process of this model and, hence, may represent a more true response of the investigating site. In addition, it may be concluded that the model can be applied to predict PGA in any site of interest around the Kaohsiung science park.

\section{Conclusion}

Without a doubt, the seismic-related problems are very important research topic in the field of disaster prevention technology. This study presented a novel way of using neural network 
approach to develop a model for learning a relationship for linking two different types of parameters, that is, the ambient vibration measurement and the on-site soil boring test data. In addition, a weight-based neural network model is also developed for predicting peak ground acceleration at an unmeasured site, and is extendable for predicting natural microtremor on any other site of the science park investigated, as long as the soil conditions are suitably distributed.

Due to the limitation of soil boring test data for each microtremor measuring station, the present study picked up only fifty sets of peak ground acceleration from each of microtremor measuring station, to match with soil profiles from five drilling holes nearby for developing neural network model. More data sets might be required to develop a more accurate model for performing the prediction. Nonetheless, the results obtained in this study provide an insight into the seismic-related characteristics in the research area. One of the significant aspects of the present research is that even though the data collected at MS1, MS2, and MS3 are for different time periods, the three neural network models developed for these sites can be combined to predict the PGA distribution at a fourth site (MS4) for a different time period.

Further, it should be mentioned that the predicted results do prove the reliability of the developed model, but the choice of microtremor measurements with commonly found frequency or peak ground acceleration should be further investigated. This may occur repeatedly and hence can affect the accuracy of precision instrument and damage products such as semiconductors or biosensors during the manufacturing process within a high-tech company. Nevertheless, the method used in this study did provide a new way to treat this type of nonlinear problem, and may be applicable in other areas of interest around the world.

\section{Acknowledgments}

The support of National Science Council under Project NSC 101-2221-E-020-030 is greatly appreciated. The authors also wish to thank Dr. J. H. Lai of KaoYuan University for providing valuable inputs including ambient vibration surveys and soil boring test data from CECI engineering consultants. Dr. D. Gunaratnam is retired recently from Faculty of Architecture, Design and Planning, University of Sydney, Australia.

\section{References}

[1] USGS, "Significant earthquake and news headlines archive," United States Geological Survey, 2011, http://earthquake.usgs.gov/earthquakes/eqinthenews/.

[2] C. R. Arjun and A. Kumar, "Neural network estimation of duration of strong ground motion using Japanese earthquake records," Soil Dynamics and Earthquake Engineering, vol. 31, no. 7, pp. 866-872, 2011.

[3] L. Frýba and J. D. Yau, "Suspended bridges subjected to moving loads and support motions due to earthquake," Journal of Sound and Vibration, vol. 319, no. 1-2, pp. 218-227, 2009.

[4] M. Hori, G. Sobhaninejad, T. Ichimura, and M. Lalith, "Enhancement of integrated earthquake simulation with high-performance computing," Journal of Earthquake and Tsunami, vol. 5, no. 3, pp. 271-282, 2011.

[5] T. Kerh, Y. Chan, and D. Gunaratnam, "Treatment and assessment of nonlinear seismic data by a genetic algorithm based neural network model," International Journal of Nonlinear Sciences and Numerical Simulation, vol. 10, no. 1, pp. 45-56, 2009.

[6] T. Kubo, Y. Hisada, M. Murakami, F. Kosuge, and K. Hamano, "Application of an earthquake early warning system and a real-time strong motion monitoring system in emergency response in a highrise building," Soil Dynamics and Earthquake Engineering, vol. 31, no. 2, pp. 231-239, 2011. 
[7] K. R. MacKie, K. J. Cronin, and B. G. Nielson, "Response sensitivity of highway bridges to randomly oriented multi-component earthquake excitation," Journal of Earthquake Engineering, vol. 15, no. 6, pp. 850-876, 2011.

[8] K. Yang and X. Liang, "A simplified method for calculating earthquake action on high-rise structures with strengthened stories," Journal of Earthquake Engineering and Engineering Vibration, no. 3, pp. 140$147,2011$.

[9] T. Kerh, T. Ku, and D. Gunaratnam, "Comparative evaluations of the seismic key parameter by artificial neural network model and ambient vibration survey," Disaster Advances, vol. 4, no. 2, pp. 5-12, 2011.

[10] T. Kerh and D. Chu, "Neural networks approach and microtremor measurements in estimating peak ground acceleration due to strong motion," Advances in Engineering Software, vol. 33, no. 11-12, pp. 733-742, 2002.

[11] A. Ojeda and J. Escallon, "Comparison between different techniques for evaluation of predominant periods using strong ground motion records and microtremors in Pereira Colombia," Soil Dynamics and Earthquake Engineering, vol. 20, no. 1-4, pp. 137-143, 2000.

[12] H. Arai and K. Tokimatsu, "S-wave velocity profiling by inversion of microtremor H/V spectrum," Bulletin of the Seismological Society of America, vol. 94, no. 1, pp. 53-63, 2004.

[13] M. A. A. Beroya, A. Aydin, R. Tiglao, and M. Lasala, "Use of microtremor in liquefaction hazard mapping," Engineering Geology, vol. 107, no. 3-4, pp. 140-153, 2009.

[14] E. H. Field, S. E. Hough, and K. H. Jacob, "Using microtremors to assess potential earthquake site response: a case study in Flushing Meadows, New York City," Bulletin of the Seismological Society of America, vol. 80, no. 6 A, pp. 1456-1480, 1990.

[15] M. S. Fnais, K. Abdelrahman, and A. M. Al-Amri, "Microtremor measurements in Yanbu city of Western Saudi Arabia: a tool for seismic microzonation," Journal of King Saud University. Science, vol. 22, no. 2, pp. 97-110, 2010.

[16] G. A. Tselentis and P. Paraskevopoulos, "Site response analysis of Vartholomio W-Greece from singular spectrum analysis of microtremor and weak motion data," Soil Dynamics and Earthquake Engineering, vol. 30, no. 5, pp. 378-394, 2010.

[17] J. Lermo and F. J. Chavez-Garcia, "Are microtremors useful in site response evaluation?" Bulletin of the Seismological Society of America, vol. 84, no. 5, pp. 1350-1364, 1994.

[18] M. I. V. Seht and J. Wohlenberg, "Microtremor measurements used to map thickness of soft sediments," Bulletin of the Seismological Society of America, vol. 89, no. 1, pp. 250-259, 1999.

[19] Central Geological Survey, "Taiwan geoscience portal," Ministry of Economic Affairs, 2011, http://www.moeacgs.gov.tw/.

[20] Central Geological Survey, "What is the distribution of active faults to cause earthquake in Taiwan?" One Hundred Geological Questions, Ministry of Economic Affairs, 2012, http://twgeoref.moeacgs .gov.tw/GipOpenWeb/wSite/ct?xItem=129493\&mp=105\&ctNode=1197.

[21] Wikipedia Encyclopedia, "Ambient vibrations," 2011, http://en.wikipedia.org/wiki/Ambient_Vibrations.

[22] Central Weather Bureau, "What is earthquake intensity?" Earthquake One Hundred Questions, No. 35, 2012, http:/ / www.cwb.gov.tw/V7/knowledge/encyclopedia/eq000.htm.

[23] Meggitt, "Model 731A ultra-quiet, ultra-low frequency, seismic accelerometer," Wilcoxon Research Inc., Gaithersburg, Md, USA, 2011, http:/ /www.wilcoxon.com/.

[24] C. J. Wu, J. H. Lai, M. H. Yang, L. Y. Chen, G. C. Mae, and H. B. Pan, "Study on the characteristics of environmental micro-tremor of Kaohsiung science park," Journal of Kao Yuan University, vol. 15, pp. 177-193, 2009.

[25] J. H. Lai, C. J. Wu, M. H. Yang, and L. Y. Chen, "Installation of environmental micro-tremor monitoring system in Kaohsiung science park," Final Report, Southern Taiwan Science Park, Taiwan, 2007.

[26] CECI Engineering Consultants, "Geologic boring and testing report," Practical Planning and Evaluation of Environmental Impact in Luchu Base of Tainan Science Park, CECI-GD-628, 2001.

[27] H. B. Seed, I. M. Idris, and I. Arango, "Evaluation of liquefaction potential using field performance data.," Journal of Geotechnical Engineering, vol. 109, no. 3, pp. 458-482, 1983.

[28] K. Terzaghi and R. B. Peck, Soil Mechanics in Engineering Practice, John Wiley \& Sons, New York, NY, USA, 1948.

[29] R. T. Wong, H. B. Seed, and C. K. Chan, "Cyclic loading liquefaction of gravelly soils," Journal of the Soil Mechanics and Foundation Division, vol. 101, pp. 571-583, 1975. 
[30] T. Kerh, D. Gunaratnam, and Y. Chan, "Neural computing with genetic algorithm in evaluating potentially hazardous metropolitan areas result from earthquake," Neural Computing and Applications, vol. 19, no. 4, pp. 521-529, 2010.

[31] S. S. S. Sakla and A. F. Ashour, "Prediction of tensile capacity of single adhesive anchors using neural networks," Computers and Structures, vol. 83, no. 21-22, pp. 1792-1803, 2005.

[32] S. V. N. Rao, B. S. Thandaveswara, S. M. Bhallamudi, and V. Srinivasulu, "Optimal groundwater management in deltaic regions using simulated annealing and neural networks," Water Resources Management, vol. 17, no. 6, pp. 409-428, 2003.

[33] D. Graupe, Introduction and Role of Artificial Neural Networks, World Scientific Publishing Company, USA, 2007.

[34] M. T. Hagan, H. B. Demuth, and M. H. Berale, Neural Network Design, PWS, Boston, Mass, USA, 1996.

[35] Y. C. Yeh, Application and Practice of Neural Networks, Rulin, Taiwan, 2009.

[36] H. C. Loh, Neural Network—Matlab Applications, Kaohli Book Company, Taiwan, 2005.

[37] S. Wu, L. Chou, S. Lee, and B. Z. Chang, Matlab Neural Networks Simulation and Application, Science Publishing Company, China, 2003. 


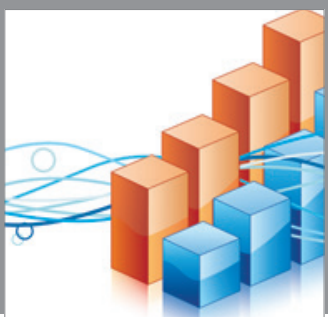

Advances in

Operations Research

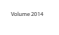

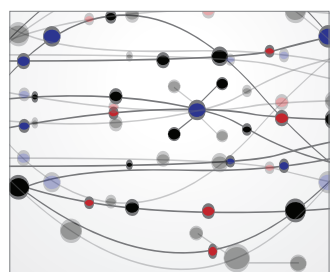

\section{The Scientific} World Journal
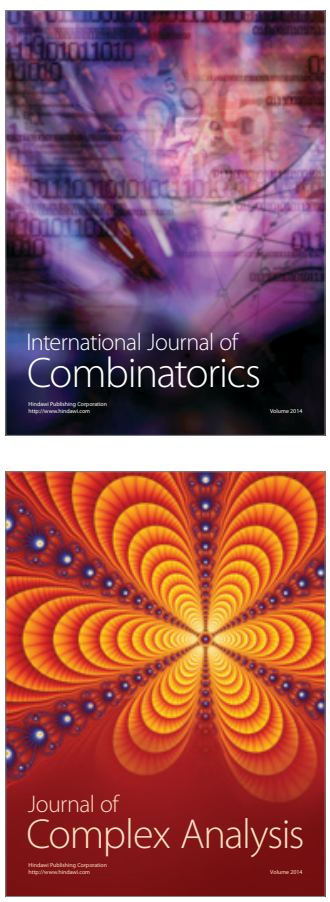

International Journal of

Mathematics and

Mathematical

Sciences
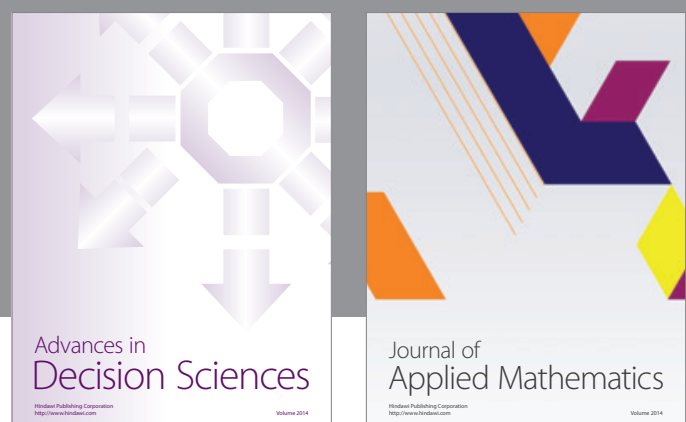

Journal of

Applied Mathematics
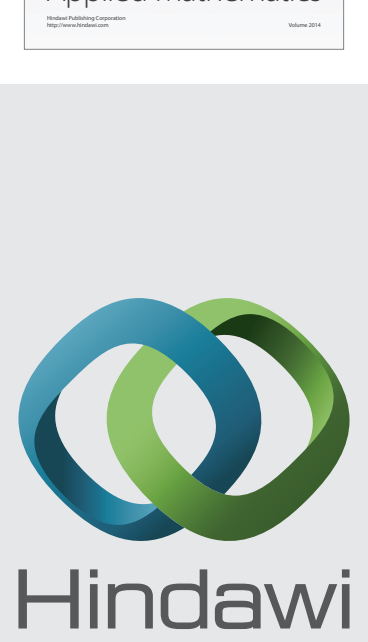

Submit your manuscripts at http://www.hindawi.com
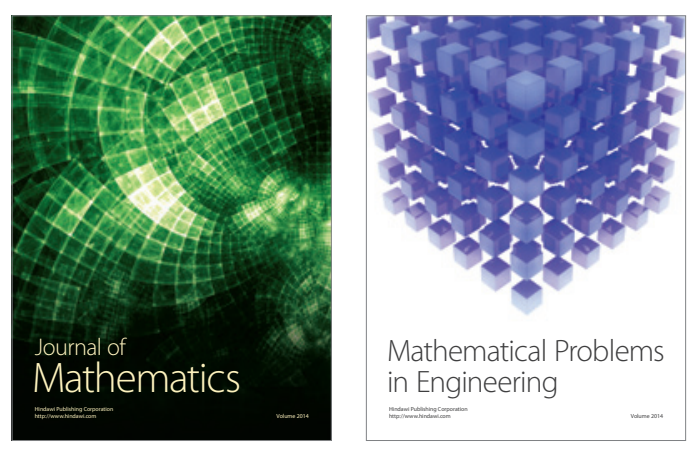

Mathematical Problems in Engineering
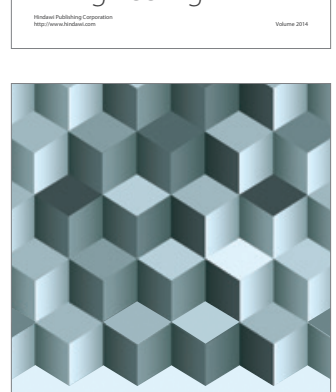

Journal of

Function Spaces
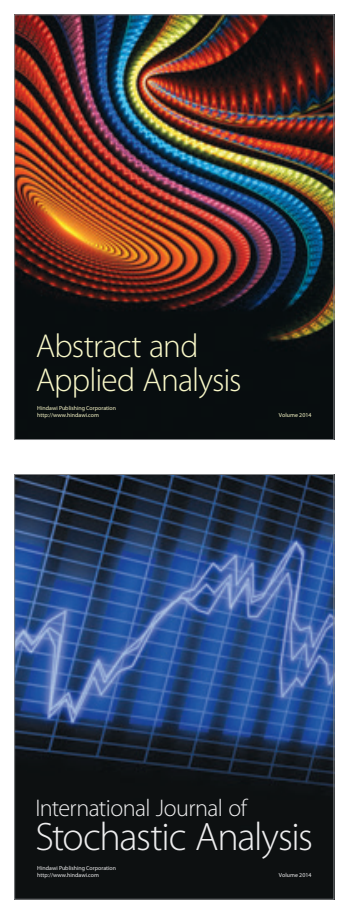

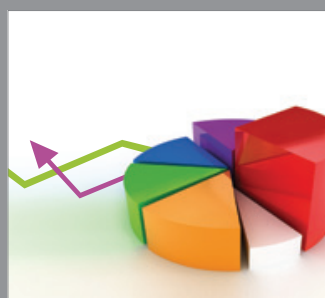

ournal of

Probability and Statistics

Promensencen
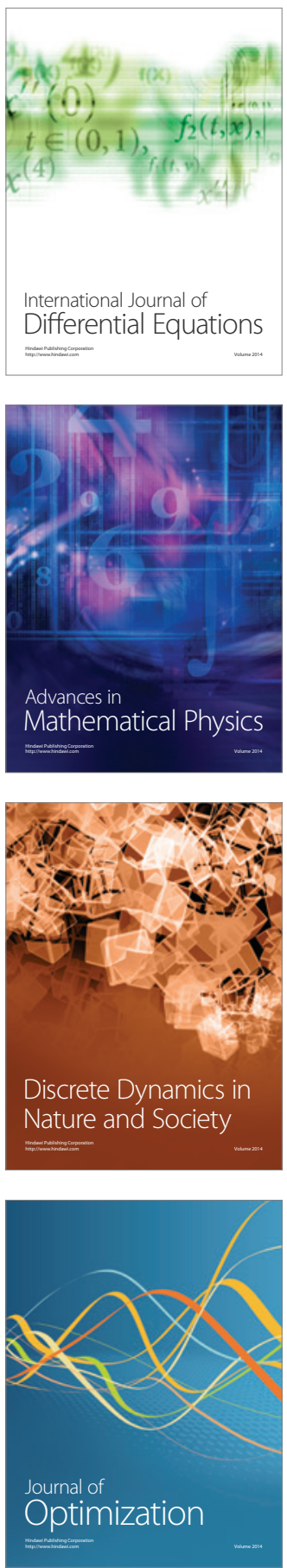